\title{
Toxoplasmosis among Egyptian children with neurological disorders: developmental and risk factors analysis
}

\section{Original Article}

\author{
Samar N El-Beshbishi ${ }^{1}$, Sara M Elzeky ${ }^{1}$, Raefa A Atia ${ }^{1}$, Khalid F Abdalaziz ${ }^{2}$, Nora L \\ El-Tantawy ${ }^{1}$
}

Department of Medical Parasitology ${ }^{1}$, and Pediatric Neurology Unit, Mansoura University Children's Hospital'2, Faculty of Medicine, Mansoura University, Mansoura, Egypt

\begin{abstract}
Background: Toxoplasma gondii is a widespread neurotropic protozoan that influences the CNS physiology with a potential role in mediating congenital and neurodevelopmental disabilities of children.

Objectives: The current study was conducted to investigate the associations between toxoplasmosis and neurodevelopmental disorders in children and to analyze the possible risk factors.

Patients and Methods: In this case control study, serum samples from 120 children with neurological disorders and 120 healthy control children were investigated for anti-Toxoplasma IgM and IgG antibodies using the enzyme-linked immunosorbent assay (ELISA). Demographics, maternal and children risk factors and developmental data of children were recorded.

Results: The seropositivity rates of both IgM and IgG anti-Toxoplasma antibodies were higher in the children group with neurodevelopmental disorders than the control group with significant difference. Statistically significant associations were found between Toxoplasma IgG seropositivity and children manifesting hydrocephaly, microcephaly, and Down syndrome. While anti-Toxoplasma IgM seropositivity was significantly associated with children manifesting epilepsy and Down syndrome. Contact with soil and farm animals was found to be a significant risk factor for toxoplasmosis in this study.

Conclusion: The findings denote that toxoplasmosis is a probable risk factor for neurodevelopmental disorders in children. This highlights the importance of toxoplasmosis consideration by pediatricians for investigating and early management of such congenital and neurodevelopmental disorders.
\end{abstract}

Keywords: children, neurodevelopmental disorders, seroprevalence, toxoplasmosis.

Received: 3 July, 2020, Accepted: 28 November, 2020.

Corresponding Author: Nora L El-Tantawy, Tel.: +20 1099931619, E-mail: noratantawy@gmail.com

Print ISSN: 1687-7942, Online ISSN: 2090-2646, Vol. 13, No. 3, December, 2020.

\section{INTRODUCTION}

Toxoplasmosis is a global parasitic disease caused by the neurotropic pathogen T. gondii. Up to half of mankind have been exposed to, or harbor this infection $^{[1]}$. The majority of human infections occur via eating raw or undercooked infected meat containing cysts, or from ingestion of contaminated food or water with sporulated oocysts ${ }^{[2]}$. Congenital infection occurs if tachyzoites in maternal blood cross the placenta and infect fetus ${ }^{[3]}$. Less frequently, infection can be transmitted by blood transfusion, solid-organ or bone marrow transplantation, or ingestion of unpasteurized milk ${ }^{[4]}$.

Toxoplasmosis usually remains asymptomatic, or it may lead to mild flu-like illness in immunocompetent individuals. Although, it can cause severe manifestations in those with compromised or diminished immune system, as AIDs patients, as well as pregnant women and newborns, respectively ${ }^{[5]}$. The severity of congenital toxoplasmosis and the rate of transmission of infection differ according to duration of pregnancy. The severity of infection increases, and the rate of transmission decreases in the first trimester and vice versa in the third trimester ${ }^{[6]}$. Outcome of congenital toxoplasmosis varies from asymptomatic infection to intrauterine fetal death or birth of severely affected children. The clinical presentations may differ from obvious defects as intrauterine growth retardation, microcephaly, and hydrocephalus to subclinical infections leading to retinochoroiditis ${ }^{[7]}$, and long-term neurodevelopmental disorders as mental retardation ${ }^{[8]}$, epilepsy ${ }^{[9]}$, schizophrenia ${ }^{[10,11]}$ and psychiatric disorders later in life ${ }^{[12]}$.

Infection can be diagnosed by serology, mouse inoculation, tissue culture of clinical specimens, and PCR. Traditionally, diagnosis of infection relies on serological detection of Toxoplasma-specific IgM and IgG antibodies in serum ${ }^{[4]}$. Given the global burden attributed to toxoplasmosis, the scarcity of research done in Egypt necessitates more studies on the effect of $T$. gondii on congenital and neurodevelopmental disabilities. This study aims to identify any association between Toxoplasma-specific IgM and/or IgG antibodies in children and neurodevelopmental disorders, and to analyze the risk factors among the recruited children and their mothers that may be associated with toxoplasmosis. This study would be beneficial in enhancing both antenatal and early childhood care side by side in the locality. 


\section{PATIENTS AND METHODS}

This case control study was conducted during the period from May 2018 to April 2019 in the laboratory of Medical Parasitology Department, Faculty of Medicine, Mansoura University.

Patients and data collection: The study was conducted on 120 patients aged from 9 months to 5 years monitored by the Neurology unit, Mansoura University Children's Hospital, Mansoura, Egypt. Group 1 included children with various forms of neurologic diseases: Down syndrome (no. $=62$ ), hydrocephalus (no. $=8$ ), microcephaly (no. = 18), attention deficit hyperactive disorder; ADHD (no. = 12), and epilepsy (no. $=20$ ). An equivalent number of apparently healthy children of similar age and sex, and from the same demographic areas were recruited as the control group 2 (no. $=120$ ). Children with history of neurosurgery, head injury or trauma, neoplastic or autoimmune diseases, or receiving immunosuppressant or systemic corticosteroid, and those with possible neurological infection, were excluded from the research.

A structured questionnaire was used for all children to collect information regarding the demographics, history of the neurodevelopmental disorder(s), risk factors, such as history of eating raw or undercooked meat, drinking of raw milk, contact with farm animals, soil and cats, as well as blood transfusion. Also, family history of other siblings, or family member/s with same condition or other neurological disorders was recorded. Besides, a questionnaire was given to the mothers of the recruited children, in order to gather data concerning Toxoplasma antenatal risk factors, as well as their personal details as history of abortion, still birth, or neonatal death, type of labor, period of gestation, and the birth weight.

Collection of blood samples: Approximately 3 $\mathrm{ml}$ venous blood was collected from each child by venipuncture, under sterile condition. Blood samples were then transported to the Department of Medical Parasitology, Faculty of Medicine, Mansoura University, within 1-2 hours. Serum was separated by centrifugation at $1000 \mathrm{rpm}$ and was then stored in labeled sterile vials at $-20^{\circ} \mathrm{C}$ according to safety practices, until used.

Serological investigation: Serum samples were kept at room temperature immediately before usage. Investigation for T. gondii-specific antibodies (IgM and IgG) was run in duplicate with negative and positive serum samples using commercial ELISA kits (BioCheck, Inc., CA, USA), which have a sensitivity and specificity of $98.3 \%$ and $99.2 \%$, respectively. Testing was done according to the manufacturer's instructions ${ }^{[13]}$. Toxoplasma indices of $\geq 1.0(>32 \mathrm{IU} / \mathrm{ml})$ were treated as positive, $<0.90(<32 \mathrm{IU} / \mathrm{ml})$ were negative, and those that were undefined between 0.91-0.99 were re-examined. Blood samples were disposed of in a safe manner after usage according to the institute guidelines.

Data analysis: Statistical analysis was done using the SPSS version 22. Numbers and percentages were used to express qualitative data. Chi-square and Fisher's exact tests were employed to test relation between categorical variables. $P$ values $\leq 0.05$ were considered statistically significant.

Ethical consideration: Ethical approval was obtained from Mansoura Faculty of Medicine-Institutional Research Board and the Ethical Review Committee of Mansoura University Children's Hospital, Faculty of Medicine, Mansoura University. Study aims and procedure of blood sample collection were explained to parents or legal guardians of the recruited children and an informed written consent was obtained for each child/mother. All children and mother's data were kept strictly confidential.

\section{RESULTS}

Sero-epidemiology of $T$. gondii in the recruited children: In this study, positive anti-T. gondii IgM was recorded in $20 \%$ of recruited children with neurological diseases (group 1) and 6.7\% of controls (group 2), with statistically significant difference $(P=0.03)$. Regarding anti-T. gondii IgG antibodies, sero-positivity rates were $38.3 \%$ and $10 \%$ in groups (1) and (2), respectively, with statistically significant difference $(P<0.001)$. Moreover, $6.7 \%$ of patients in group (1) and 3.3\% from the controls had both T. gondii IgM and IgG antibodies. There were no significant differences between Toxoplasma-specific IgM and/or IgG seropositivity rates in the children concerning any of the measured demographics; age, sex, and site of residence (Table 1).

Anti-T. gondii antibodies and neurological manifestations: Table (2) showed statistically significant associations $(P<0.05$ for each variable $)$ between Toxoplasma IgM sero-positivity and group of children manifested with epilepsy and Down syndrome, between Toxoplasma IgG seropositivity and children group manifested with microcephaly, hydrocephalus and Down syndrome, as well as between combined positive anti-T. gondii IgM/IgG and Down syndrome. On the other hand, there was no significant correlation between T. gondii antibodies and ADHD.

Analysis of risk factors of $T$. gondii infection: A significant association was recorded only between contact with farm animals/soil as a risk factor and toxoplasmosis seropositivity in group (1). Analysis of anti-T. gondii sero-positivity of children and the obstetric history of their mothers revealed no statistically significant correlation between them in both groups (Table 3 ). 
PARASITOLOGISTS UNITED JOURNAL

Table 1. Sero-positivity rates of anti-T. gondii IgM and IgG antibodies in the studied children.

\begin{tabular}{|c|c|c|c|}
\hline \multirow{2}{*}{ Toxoplasma antibodies } & Group 1 (no.=120) & Group 2 (no.=120) & Statistical analysis \\
\hline & $\mathrm{N}(\%)$ & $N(\%)$ & $P$ value \\
\hline Positive IgM (Toxplasma index $\geq 1.00$ ) & $24(20.0)$ & $8(6.7)$ & $\chi^{2}=4.61, P=0.03^{*}$ \\
\hline Positive IgG (Toxoplasma index $\geq 1.00$ ) & $46(38.3)$ & $12(10)$ & $\chi^{2}=13.14, P<0.001^{*}$ \\
\hline Positive combined IgM \& IgG & $8(6.7)$ & $4(3.3)$ & FET, $P=0.67$ \\
\hline
\end{tabular}

Group 1: Children with different forms of neurologic disorders; Group 2: Controls; no.: Number examined; N: Number positive; $\boldsymbol{X}^{2}$ : Chi-Square test; FET: Fischer's exact test; *Statistically significant $(P \leq 0.05)$; Toxoplasma index: Sample mean value/calibrator mean value.

Table 2. Relation between anti-T. gondii antibodies and neurological diseases of children.

\begin{tabular}{lcccccc}
\hline \hline Clinical & \multicolumn{2}{c}{ IgM (no. = 24) } & \multicolumn{2}{c}{ IgG (no. = 46) } & \multicolumn{2}{c}{ Combined Igs (no. = 8) } \\
\cline { 2 - 6 } Manifestations (no.) & $\mathbf{N}(\%)$ & $\boldsymbol{P}$ value & N (\%) & P value & N (\%) & P value \\
\hline Microcephaly (18) & $6(25.0)$ & 0.28 & $14(30.4)$ & $0.008^{*}$ & $4(50)$ & 0.1 \\
Hydrocephalus (8) & $0(0)$ & 0.57 & $8(17.4)$ & $0.009^{*}$ & $0(0)$ & 1.0 \\
ADHD (12) & $6(25.0)$ & 0.08 & $6(13.0)$ & 0.67 & $2(25)$ & 0.35 \\
Epilepsy (20) & $10(41.7)$ & $0.009^{*}$ & $6(21.7)$ & 0.41 & $2(25)$ & 0.53 \\
Down syndrome (62) & $2(8.3)$ & $0.001^{*}$ & $8(17.4)$ & $<0.001^{*}$ & $0(0)$ & $0.049^{*}$ \\
\hline \hline
\end{tabular}

no.: Number examined; N: Number positive; Combined Igs: Combined IgM/IgG positive; ADHD: Attention deficit hyperactive disorder; *Statistically significant $(P \leq 0.05)$.

Table 3. Correlation between children exposure to risk factors and the obstetric history of their mothers and toxoplasmosis seropositivity.

\begin{tabular}{|c|c|c|c|c|c|c|c|c|}
\hline \multirow[t]{2}{*}{ Risk factors } & \multicolumn{4}{|c|}{ Combined Igs in group (1) } & \multicolumn{4}{|c|}{ Combined Igs in group (2) } \\
\hline & no. & N (\%) & $P$ value & Odds ratio & no. & $\mathrm{N}(\%)$ & $P$ value & Odds ratio \\
\hline \multicolumn{9}{|l|}{ Children } \\
\hline Artificial feeding & 22 & $2(25)$ & 0.57 & $1.5(0.14-16.31)$ & 8 & 0 & 1.0 & UD \\
\hline Drinking raw milk & 36 & 0 & 0.17 & UD & 0 & 0 & 0 & UD \\
\hline Eating raw or undercooked meat & 32 & $4(50)$ & 0.29 & $3.0(0.39-23.33)$ & 92 & $4(100)$ & 1.0 & UD \\
\hline \multicolumn{9}{|l|}{ Contact } \\
\hline With cats & 24 & $4(50)$ & 0.85 & $0.81(0.11-6.14)$ & 66 & 0 & 1.0 & UD \\
\hline With farm animals or soil & 34 & $6(75)$ & $0.03 *$ & $9.0(0.86-93.7)$ & 84 & $4(100)$ & 0.9 & UD \\
\hline \multicolumn{9}{|l|}{ Mothers } \\
\hline Abortion & 94 & $6(75)$ & 0.87 & $0.81(0.08-8.6)$ & 8 & 0 & 1.0 & UD \\
\hline Stillbirth & 20 & 0 & 0.36 & UD & 20 & 0 & 1.0 & UD \\
\hline Intrauterine fetal death & 34 & $4(50)$ & 0.32 & $2.73(0.35-21.17)$ & 24 & 0 & 1.0 & UD \\
\hline \multicolumn{9}{|l|}{ Contact } \\
\hline With cats & 120 & $8(100)$ & & & 120 & $4(100)$ & & UD \\
\hline With farm animals or soil & 120 & $8(100)$ & & & 120 & $4(100)$ & & UD \\
\hline Eating raw or undercooked meat & 38 & $2(25)$ & 1.0 & $0.70(0.07-7.24)$ & 4 & 0 & 0.1 & UD \\
\hline Drinking raw milk & 36 & 0 & 0.31 & UD & 0 & 0 & 0 & UD \\
\hline \multicolumn{9}{|l|}{ Type of labor } \\
\hline Vaginal & 74 & 30 & 0.58 & $1.34(0.47-3.84)$ & 84 & 50 & 0.56 & $1.9(0.51-3.53)$ \\
\hline Cesarean & 46 & 22 & & & 36 & 16 & & \\
\hline \multicolumn{9}{|l|}{ Gestational age } \\
\hline Full term & 112 & $4(100)$ & 1.0 & UD & 38 & $6(75)$ & 0.9 & $7.5(0.73-77.6)$ \\
\hline Preterm & 8 & 0 & & & 82 & $2(25)$ & & \\
\hline \multicolumn{9}{|l|}{ Birth weight } \\
\hline Normal & 120 & $4(100)$ & & & 30 & $4(50)$ & 0.23 & $3.3(0.42-25.8)$ \\
\hline Low & 0 & 0 & & & 90 & $4(50)$ & & \\
\hline
\end{tabular}


Anti-T. gondii antibodies and other evaluated parameters: No significant association was detected between Toxoplasma-specific antibodies and the neurological disabilities assessed except for positive Toxoplasma antibodies and combined motor and mental delay in Down syndrome $(P=0.02)$ (Table 4). It is worth mentioning that there was no significant association between Toxoplasma seropositivity, and growth parameters; weight and height (data not shown). Regarding seropositivity and family history of children, there was significant association in both groups: In group (1), eight cases with positive IgM and four cases with positive combined IgM/IgG had family history of other siblings with same condition $(P=0.004$ and 0.03 , respectively). In group (2), there was significant association between IgG positivity and the family history of other neurological diseases $(P=0.04)$ (Table 5).

Table 4. Relation between anti-T. gondii antibodies and developmental parameters of children with neurological diseases.

\begin{tabular}{|c|c|c|c|c|c|}
\hline & & \multicolumn{4}{|c|}{ Developmental delay } \\
\hline & & Motor & Mental & Motor and mental & Mental and speech \\
\hline \multirow[t]{3}{*}{ Down } & no. $=62$ & 2 & 16 & 34 & 10 \\
\hline & Toxoplasma Ig +ve [N (\%)] & 0 & 0 & 0 & $10(100)$ \\
\hline & $P$ value & 1.0 & 0.15 & $0.02^{*}$ & 0.28 \\
\hline \multirow[t]{3}{*}{ Hydrocephalus } & no. $=8^{(a)}$ & 6 & 0 & 0 & 0 \\
\hline & Toxoplasma Ig +ve [N (\%)] & $6(75)$ & 0 & 0 & 0 \\
\hline & $P$ value & 1.0 & - & - & - \\
\hline \multirow[t]{3}{*}{ Microcephaly } & no. $=18^{(\mathrm{b})}$ & 10 & 0 & 4 & 2 \\
\hline & Toxoplasma Ig +ve [N (\%)] & $8(50)$ & 0 & $4(25)$ & $2(12.5)$ \\
\hline & $P$ value & 1.0 & - & 1.0 & 1.0 \\
\hline \multirow[t]{3}{*}{ ADHD } & no. $=12^{(\mathrm{a}, \mathrm{b})}$ & 4 & 0 & 0 & 4 \\
\hline & Toxoplasma Ig +ve [N (\%)] & $2(20)$ & 0 & 0 & $4(100)$ \\
\hline & $P$ value & 0.33 & - & - & 1.0 \\
\hline \multirow[t]{3}{*}{ Epilepsy } & no. $=20^{(a, c)}$ & 10 & 0 & 0 & 4 \\
\hline & Toxoplasma Ig + ve [N (\%)] & $8(44.4)$ & 0 & 0 & $4(22.2)$ \\
\hline & $P$ value & 1.0 & - & - & 1.0 \\
\hline
\end{tabular}

no.: Number examined, N: Number positive; ADHD: Attention deficit hyperactive disorder; Toxoplasma Ig+ve: Number of Toxoplasma-positive children (either isolated IgM or IgG or combined IgM/IgG). *Statistically significant $(P \leq 0.05)$. a: Two cases were associated with speech delay, b, c: Two and four cases with no developmental delay, respectively.

Table 5. Association between T. gondii seropositivity and family history of the recruited children.

\begin{tabular}{|c|c|c|c|c|c|c|c|c|}
\hline & & \multicolumn{7}{|c|}{ Family history } \\
\hline & & \multicolumn{2}{|c|}{$\begin{array}{c}\text { Siblings with } \\
\text { same condition }\end{array}$} & \multicolumn{2}{|c|}{$\begin{array}{c}\text { Other members with } \\
\text { same condition }\end{array}$} & \multicolumn{3}{|c|}{$\begin{array}{c}\text { Other neurological } \\
\text { disease }\end{array}$} \\
\hline & no. & 10 & & & 10 & & 18 & \\
\hline \multirow[t]{7}{*}{ Group 1} & IgM +ve [N (\%)] & $8(33.3)$ & & $2(8.3)$ & & $4(16.7)$ & & \\
\hline & $P$ value & $0.004^{*}$ & & 1.0 & & 0.86 & & \\
\hline & IgG +ve [N (\%)] & $6(13)$ & & & $6(13)$ & & $6(13)$ & \\
\hline & $P$ value & 0.36 & & & 0.36 & & 0.74 & \\
\hline & Combined Igs +ve [N (\%)] & & $4(50)$ & & $2(25)$ & & & $2(25)$ \\
\hline & $P$ value & & $0.03^{*}$ & & 0.30 & & & 0.49 \\
\hline & no. & $\mathbf{0}$ & & & $\mathbf{0}$ & & 8 & \\
\hline \multirow[t]{6}{*}{ Group 2} & IgM +ve [N (\%)] & 0 & & 0 & & 0 & & \\
\hline & $P$ value & -- & & -- & & 0.58 & & \\
\hline & IgG +ve [N (\%)] & 0 & & & 0 & & $4(33.3)$ & \\
\hline & $P$ value & -- & & & -- & & $0.04^{*}$ & \\
\hline & Combined Igs +ve [N (\%)] & & 0 & & 0 & & & 0 \\
\hline & $P$ value & & -- & & -- & & & 1.0 \\
\hline
\end{tabular}




\section{DISCUSSION}

The neurotropic affinity of T. gondii can influence the CNS physiology ${ }^{[14]}$, hence it is able to mediate neurodevelopmental disorders of children affecting their mentality and behavior ${ }^{[8,15-17]}$. In this study, the overall prevalence of toxoplasmosis was $51.7 \%$ in children with neurodevelopmental disorders compared to $13.3 \%$ in controls. The seropositivity of anti-T. gondii IgM, IgG and combined IgM/IgG were $20 \%, 38.3 \%$ and $6.7 \%$ among children with neurological manifestations and $6.7 \%, 10 \%$ and $3.3 \%$ in the control group, respectively, with significant differences except for the combination of both immunoglobulins. This difference mirrors a plausible association between toxoplasmosis and neurological disorders. The results corroborated those of our preliminary study on 30 children suffering from central nervous system manifestations without obvious chromosomal anomalies, 30 children with Down syndrome and 30 healthy children ${ }^{[18]}$. This association was also previously reported by Zaki et $a{ }^{[19]}$ who detected a high seropositivity of antiToxoplasma IgG (35.8\% vs $14.8 \%)$ in neuropsychiatric patients at KSA than controls, but no significant association was reported between anti-Toxoplasma IgM seropositivity and neuropsychiatric disorders. Also, Shehata et al. ${ }^{[20]}$ studied T. gondii infection among patients with neurodevelopmental disorders and recorded a seropositivity of $16.5 \%$ and $50 \%$ for IgM and IgG, respectively, and determined a significant association between anti-Toxoplasma IgG but not IgM seropositivity and neurodevelopmental disorders. These variations in the seropositivity rates may be explained by using different diagnostic tests, study population manifestations, age group, sample size, study area, number of handled cats and their infectivity, methods of infection and geographical variations ${ }^{[21]}$.

Reviewing the literature, there are many explanations for such association between toxoplasmosis and neural disruption which include many anatomical, immunocellular and neurotransmitter-related changes which occur after toxoplasmosis, and consequently play a significant role in the development of neurological disorders ${ }^{[22,23]}$. Toxoplasmosis may cause alternations in neurotransmitter levels like serotonin, noradrenaline, glutamate, nitric oxide and gamma aminobutyric acid ${ }^{[24]}$, increase in the levels of pro-inflammatory cytokines ${ }^{[25]}$ and modulate the dopaminergic signaling ${ }^{[26]}$. The behavioral changes produced by cyst formation in the brain tissue in response to toxoplasmosis may also be related to the localization of the cyst within specific parts of the brain coma ${ }^{[23]}$ and this is assumed to be one of the main causes of epilepsy in patients with toxoplasmosis ${ }^{[27]}$. Moreover, tachyzoites may invade the brain tissues and excite brain cells especially neurons, microglia and astrocytes ${ }^{[28]}$. Additionally, the presence of Toxoplasma in the brain provokes inflammatory response and stimulates the immune system to produce antibodies against autoantigens and so increase the synthesis and secretion of proinflammatory cytokines ${ }^{[29]}$. Interestingly, Brynska et $a l^{[30]}$ described that many host genes and proteins could be affected by toxoplasmosis, signifying its involvement in many genetic disorders, particularly psychiatric diseases.

Our results show rates of $8.3 \%$ and $17.4 \%$ seropositivity for anti-Toxoplasma IgM and IgG respectively among children group manifested by Down syndrome with a statistically significant association between Down syndrome and toxoplasmosis in comparison to control group. To our best knowledge, there is no previous data on the relation between children with Down syndrome and T. gondii seropositivity except our previous study ${ }^{[18]}$ that demonstrated seropositivity rates of $3.33 \%$ and $13.33 \%$, respectively. However, the study of Shehata et $a .^{[20]}$ reported higher rates of anti-T. gondii IgM and IgG antibodies in patients with Down syndrome $(10.3 \%$ and $34.5 \%$, respectively). This may due to the different age groups between the two studies. Worthwhile, T. gondii is an intracellular parasite affecting the chromatin structure of infected cell ${ }^{[31]}$, so it may be a causative agent for developing Down syndrome. Furthermore, in T. gondii-chronically infected mice, some genes were found to be over expressed in the brain ${ }^{[22]}$ as S100b, a calcium-binding protein produced and expressed by astrocytes $^{[32]}$. Significantly increased S100b protein in amniotic fluid of pregnancies with Down syndrome may suggest association between T. gondii infection and development of Down syndrome ${ }^{[33]}$. Moreover, a previous study recorded that DNA hypomethylation can influence chromosomal structure and gene expression $^{[34]}$ and T. gondii infection can cause DNA hypomethylation in peripheral blood cells, signifying an association between Down syndrome and T. gondii infection ${ }^{[35]}$.

In our study, there was no statistically significant association between developmental parameters and Toxoplasma seropositivity except for combined motor and mental delay in children with Down syndrome. However, higher rates of Toxoplasma seropositivity were recorded among children with various types of developmental delay. These high rates agree with other Egyptian studies conducted by Ameri et al. ${ }^{[36]}$ that recorded $43.75 \%$ prevalence rate of anti-T. gondii IgG in children with unknown cause of intellectual disability, and by Shehata et al. ${ }^{[20]}$, that documented IgM and IgG antibodies in $15.5 \%$ and $49.6 \%$ of patients with speech and language development delay, respectively. Also, another Egyptian study reported a significant $(P<0.001)$ seroprevalence of toxoplasmosis among mentally retarded patients $(42 \%)$ in comparison with control group $(17.5 \%)^{[8]}$.

In Brazil, Caiaffa et al. ${ }^{[37]}$ reported $55 \%$ prevalence rate of $T$. gondii infection in intellectually disabled 
patients. However, a lower result was observed by Ezatpour et al. ${ }^{[38]}$ who assessed 14 mentally retarded children below 10 years in Iranian rehabilitation centers and reported that only one case (7.1\%) had anti-T. gondii IgG antibodies. Abdoli et al. ${ }^{[39]}$ suggested that $T$. gondii infection can affect the dopamine systems in offspring leading to delayed motor development, increased prevalence of mental retardation and cognitive delays, besides increased risks of some neuropsychiatric disorders.

No significant association was observed between Toxoplasma seropositivity in children and any of the questioned risk factors either for children or mothers except for the contact with farm animals/soil. This association was previously reported ${ }^{[40,41]}$ and it reflects personal hygiene problems in these children besides environmental contamination with T. gondii oocysts ${ }^{[41]}$. The modesty of the sample size for the analysis of the risk factor for toxoplasmosis was a limitation and this may explain the non-significant results of other risk factors.

In conclusion, Toxoplasma seropositivity rates in children with neurodevelopmental disorders are significantly higher than control group postulating that Toxoplasma infection may have consequences on the nervous system of the affected children leading to neurodevelopmental disorders. The findings of this study suggest that there is a significant correlation between toxoplasmosis and Down syndrome which needs further research on a large scale to assess this association. Future efforts are necessary to delineate the mechanism/s by which toxoplasmosis affects brain and causes neurodevelopmental disorders in children and to define the most probable Toxoplasma genotype responsible for that.

Authors contribution: El-Beshbishi SN and El-Tantawy NL contributed equally to the concept/study design, supervision of the laboratory work, data analysis and interpretation, and writing the manuscript. Elzeky SM collected data and samples, conducted the laboratory investigations, analysed data, and helped in drafting the manuscript. Atia RA supervised the laboratory work, and reviewed data for intellectual content. Abdalaziz KF collected and clinically examined the recruited children and supervised the work. All authors approved the final version.

Conflict of interest: The authors declare that they do not have any conflict of interest.

Funding statement: No funding.

\section{REFERENCES}

1. WHO. 2015 Available at: http://www.euro.who. int/_data/assets/pdf_file/0011/294599/FactsheetToxoplasmosis-en.pdf?ua=1, accessed April 2020.
2. Elmore SA, Jones JL, Conrad PA, Patton S, Lindsay DS, Dubey JP. Toxoplasma gondii: epidemiology, feline clinical aspects, and prevention. Trends Parasitol 2010; 26(4):190-196.

3. Montoya JG, Remington JS. Management of Toxoplasma gondii infection during pregnancy. Clin Infect Dis 2008; 47(4): 554-566.

4. Robert-Gangneux F, Dardé ML. Epidemiology of and diagnostic strategies for toxoplasmosis. Clin Microbiol Rev 2012; 25 (2): 264-296

5. Dubey JP. The history of Toxoplasma gondii: the first 100 years. J Eukaryot Microbiol 2008; 55 (6):467-475.

6. Li XL, Wei HX, Peng H., Lindsay DSA. Meta-analysis on risks of adverse pregnancy outcomes in Toxoplasma gondii infection. PLoS One 2014; 9(5): e97775.

7. Jones LA, Alexander J, Roberts CW. Ocular toxoplasmosis: in the storm of the eye. Parasite Immunol 2006; 28(12): 635-642.

8. Hamed AMR, El-Gebaly NSM, Abdelmegeid AK, Elsebaei ES. Seroprevalence of Toxoplasma gondii infection in mentally retarded children in Egypt. PUJ 2018; 11(3):155-161.

9. Ngoungou Eb, Bhalla D, Nzoghe A, Dardé M, Preux P. Toxoplasmosis and epilepsy: Systematic review and meta-analysis. PLoS Negl Trop Dis 2015; 9(2): e0003525.

10. Ansari-Lari M, Farashbandi H, Mohammadi F. Association of Toxoplasma gondii infection with schizophrenia and its relationship with suicide attempts in these patients. TMIH 2017; 22(10):1322-1327.

11. El-Gebaly NSM, Abd-Eltawab MSA, Hamed AMR, Mahfouz NA, Abdelmaksoud R, Adel S, et al. Insights into the interplay of latent toxoplasmosis, testosterone, cortisol and oxidative stress in screened schizophrenic patients in Egypt. PUJ 2019; 12(2): 102-109.

12. McAuley JB. Congenital toxoplasmosis. J Pediatric Infect Dis Soc 2014; 3(1): 30-35.

13. Filice G, Meroni V, Carnevale G, Olliaro P, Carosi G. Comparison of ELISA and indirect immunofluorescence in the detection of $\operatorname{IgG}$ and IgM anti-Toxoplasma antibodies. Boll Ist Sieroter Milan 1983; 62:445-450.

14. Mendez OA, Koshy AA. Toxoplasma gondii: Entry, association, and physiological influence on the central nervous system. PLoS Pathog 2017; 13(7):1006351.

15. Jones JL, Kruszon-Moran D, Wilson M. Toxoplasma gondii Infection in the United States, 1999-2000. Emerg Infect Dis 2003; 9(11): 1371-1374.

16. Hinze-Selch D, Daubener W, Erdag S, Wilms S. The diagnosis of a personality disorder increases the likelihood for seropositivity to Toxoplasma gondii in psychiatric patients. Folia Parasitol 2010; 57,129-135.

17. Fekadu A, Shibre T, Cleare AJ. Toxoplasmosis as a cause for behavior disorders: overview of evidence and mechanisms. Folia Parasitol 2010; 57,105-113.

18. El-Beshbishi SN, El-Tantawy NL, Elzeky SM, Abdalaziz KF, Atia RA. Seroprevalence of Toxoplasma gondii infection in children with central nervous system disorders in Mansoura, Egypt: a case-control study. Tran Roy Soc Trop Med Hyg 2018; 112(12), 555-560.

19. Zaki WM, Hofdi RY, Shebiley AA, Saadi ZA, Ageel AH. Sero-prevalence of Toxoplasma gondii infection and its 
associated risk factors in neuropsychiatric patients in Jazan Province, Saudi Arabia. J Egypt Soc Parasitol 2016; 46(3):467-474.

20. Shehata AI, Hassanein FI, Abdul Ghani R. Seroprevalence of Toxoplasma gondii infection among patients with non-schizophrenic neuro-developmental disorders in Alexandria, Egypt. Acta Trop 2016; 154:155-159.

21. Kistiah K, Barragan A, Winiecka-Krusnell J, Karstaedt A, Frean J. Seroprevalence of Toxoplasma gondii infection in HIV-positive and HIV-negative subjects in Gauteng, South Africa. South Afr J Epidemiol Infect 2011; 26: 225-228.

22. Hermes G, Ajioka JW, Kelly KA, Mui E, Roberts F, Kasza $\mathrm{K}$ et al. Neurological and behavioral abnormalities, ventricular dilatation, altered cellular functions, inflammation, and neuronal injury in brains of mice due to common, persistent, parasitic infection. J Neuroinflammation 2008; 5:48.

23. McConkey GA, Martin HL, Bristow GC, Webster JP. Toxoplasma gondii infection and behaviour - location, location, location? J Exp Biol 2013; 216(1):113-119.

24. Babaie J, Sayyah M, Choopani S, Asgari T, Golkar M, Gharagozli K. Toxoplasmosis accelerates acquisition of epilepsy in rats undergoing chemical kindling. Epilepsy Res 2017; 135:137-142.

25. Bottari NB, Baldissera MD, Tonin AA, Rech VC, Nishihira VSK, Thomé GR et al. Effects of sulfamethoxazoletrimethoprim associated to resveratrol on its free form and complexed with 2-hydroxypropyl- $\beta$-cyclodextrin on cytokines levels of mice infected by Toxoplasma gondii. Microb Pathog 2015; 87:40-44.

26. Prandovszky E, Gaskell E, Martin H, Dubey JP, Webster JP, McConkey GA. The neurotropic parasite Toxoplasma gondii increases dopamine metabolism. PLoS One 2011; 6(9): e23866.

27. Palmer BS. Meta-analysis of three case-controlled studies and an ecological study into the link between cryptogenic epilepsy and chronic toxoplasmosis infection. Seizure 2007; 16(8):657-663.

28. Carruthers VB, Suzuki Y. Effects of Toxoplasma gondii infection on the brain. Schizophr Bull 2007; 33(3):745751.

29. Fabiani S, Pinto B, Bruschi F. Toxoplasmosis and neuropsychiatric diseases: can serological studies establish a clear relationship? Neurol Sci 2013; 34:417425.

30. Brynska A, Wolanczyk T, Tomaszewicz-Libudzic C. OCD and acquired toxoplasmosis comorbidity in three children. Eur Psychiatry 1997; 12(2):222.
31. Leng J, Denkers EY. Toxoplasma gondii inhibits covalent modification of histone $\mathrm{H} 3$ at the IL-10 promoter in infected macrophages. PLoS One 2009; 4(10): e7589.

32. Griffin WS, Stanley LC, Ling C, White L, MacLeod V, Perrot LJ et al. Brain interleukin 1 and S-100 immunoreactivity are elevated in Down syndrome and Alzheimer disease. Proc Natl Acad Sci U S A 1989; 86(19):7611-7615.

33. Netto CB, Siqueira IR, Fochesatto C, Portela LV, Tavares M, Souza DO et al. S100B content and SOD activity in amniotic fluid of pregnancies with Down syndrome. Clin Bioch 2004; 37:134-137.

34. Agrawal A, Murphy RF, Agrawal DK. DNA methylation in breast and colorectal cancers. Mod Pathol 2007; 20:711-721.

35. Ribeiro DA, Pereira PCM, Machado JM, Silva SB, Pessoa AWP, Salvadori DMF. Does toxoplasmosis cause DNA damage? An evaluation in isogenic mice under normal diet or dietary restriction. Mutat Res 2004; 559:169176.

36. Amrei MA, Al-Hamshary AM, Fotoh OA, Abdel-Rahman S. Studies on prenatal infections in children with unknown cause of mental retardation and examination of their mothers. J Egypt Soc Parasitol 1999; 29(1): 59-67.

37. Caiaffa W, Chiari C, Figueiredo A, Orefice F, Antunes CM. Toxoplasmosis and mental retardation report of a case-control study. Mem Inst Oswaldo Cruz 1993; 88: 253-261.

38. Ezatpour B, Zibaie M, Rahmati H, Pournia Y, Azami M, Ebrahimzadeh F et al. Sero-prevalence of toxoplasmosis in mentally retarded patients in Iranian rehabilitation centers. J Parasit Dis 2015; 39(1): 13-17.

39. Abdoli A, Dalimi A, Arbabi M, Ghaffarifar F. Neuropsychiatric manifestations of latent toxoplasmosis on mothers and their offspring. J Matern Fetal Neonatal Med 2014; 27:1368-1374.

40. El Deeb HK, Salah-Eldin H, Khodeer S, Allah AA. Prevalence of Toxoplasma gondii infection in antenatal population in Menoufia Governorate, Egypt. Act Trop 2012; 124: 185-191.

41. Chintapalli S, Padmaja IJ. Seroprevalence of toxoplasmosis in antenatal women with bad obstetric history. Trop Parasitol 2013; 3(1): 62-66.

42. Al-Kappany YM, Rajendran C, Ferreira LR, Kwok OCH, Abu-Elwafa SA, Hilali $\mathrm{M}$ et al. High prevalence of toxoplasmosis in cats from Egypt: isolation of viable Toxoplasma gondii, tissue distribution, and isolate designation. J Parasitol 2010; 96(6):1115-1118. 